\title{
OPEN Evaluation of human exposure to parabens in north eastern Poland through hair sample analysis
}

\author{
Joanna Wojtkiewicz ${ }^{1 凶}$, Manolis Tzatzarakis² ${ }^{2}$ Elena Vakonaki² ${ }^{2}$ Krystyna Makowska ${ }^{3}$ \& \\ Slawomir Gonkowski ${ }^{4}$
}

Parabens (PBs) are a group of substances commonly used in industry. They also pollute the environment, penetrate into living organisms and adversely affect various internal organs. During this study, the degree of exposure of people living in Olsztyn, a city in north eastern Poland, to selected parabens most often used in industry was studied. The chemicals under investigation included: methyl paraben-MePB, ethyl paraben-EtPB, propyl paraben-PrPB, benzyl paraben BePB and butyl paraben -BuPB. To this aim, hair samples collected from the scalps of 30 volunteers were analyzed using a liquid chromatography-mass spectrometry technique. All PBs studied were present in a high percentage of analyzed samples (from $76.7 \%$ in the case of BePB to $100 \%$ in the case of MePB and PrPB). The mean concentration levels were $4425.3 \mathrm{pg} / \mathrm{mg}$ for MeBP, $704.0 \mathrm{gg} / \mathrm{mg}$ for EtPB, $825.7 \mathrm{pg} / \mathrm{mg}$ for PrPB, $135.2 \mathrm{pg} / \mathrm{mg}$ for BePB and $154.5 \mathrm{pg} / \mathrm{mg}$ for BuPB. Significant differences in PB concentration levels between particular persons were visible. On the other hand, gender, age and artificial hair coloring did not cause statistically significant differences in PB levels. Obtained results have clearly indicated that people living in north eastern Poland are exposed to various PBs, and therefore these substances may affect their health status. However, the evaluation of PBs influence on human health requires further research.

Parabens (PBs) are a large group of organic substances, which are the alkyl esters of parahydroxybenzoic acid, that differ among themselves by their functional groups ${ }^{1}$. PBs may be synthesized by some species of microbes and plants, but more often there are synthetic parabens commonly used in various branches of industry since the $1930 \mathrm{~s}^{1,2}$. These substances play an important role in food, chemical, and cosmetics production, and they are included into many everyday objects, such as personal care products, shampoo, lipsticks, food packaging, baby wipes, drugs and many others ${ }^{1,3,4}$. PBs with short-chain functional groups, such as methyl paraben (MePB), ethyl paraben $(\mathrm{EtPB})$, propyl paraben $(\mathrm{PrPB})$ and butyl paraben $(\mathrm{BuPB})$ are especially often used in the industry ${ }^{1}$.

$\mathrm{PBs}$ penetrate from the above-mentioned objects into the environment. Up to now, these substances have been detected in different parts of the world in water (both tap and surface), human food, animal food, soil and dust ${ }^{5-10}$ ). PBs can also enter living organisms through the respiratory tract, gastrointestinal systems, skin and placenta (in utero) ${ }^{11,12}$. Previous studies have reported the presence of PBs in human blood, urine, seminal plasma, tissues and hair ${ }^{13,14}$.

For decades PBs were considered to be completely safe for living organisms, but since the end of the twentieth century more and more studies have reported their adverse effects on humans and animals. Currently PBs are classified as endocrine disruptors, which have genotoxic and cytotoxic effects ${ }^{15,16}$ and affect many internal organs and systems, mainly including the reproductive, immune and endocrine systems ${ }^{17-20}$. Some studies have also reported correlations between PBs and obesity, disorders in the nervous system developmental disorders and neoplastic processes ${ }^{11,21-23}$. Due to adverse effects of PBs, the legislation of many countries has introduced

\footnotetext{
${ }^{1}$ Department of Pathophysiology, School of Medicine, Collegium Medicum, University of Warmia and Mazury, 10-900 Olsztyn, Poland. 'Laboratory of Toxicology Science and Research, Medicine School, University of Crete, 70013 Heraklion, Crete, Greece. ${ }^{3}$ Department of Clinical Diagnostics, Faculty of Veterinary Medicine, University of Warmia and Mazury in Olsztyn, Oczapowskiego 14, 10-957, Olsztyn, Poland. "Department of Clinical Physiology, Faculty of Veterinary Medicine, University of Warmia and Mazury in Olsztyn, Oczapowskiego 13, 10-957, Olsztyn, Poland. ${ }^{\bowtie}$ email: joanna.wojtkiewicz@uwm.edu.pl
} 
the limitation of these substances. The permitted content of PBs in cosmetics in the European Union amounted to $0.4 \%$ for one $\mathrm{PB}$ and $0.8 \%$ for all $\mathrm{PBs}^{24}$.

Due to the negative multidirectional impact of PBs on human health described in recent years, as well as the widespread presence of these compounds in the human environment, the monitoring of human exposure to parabens by determining their levels in the tissues and fluids of the body has become an important problem in modern toxicology. Until now, the human exposure to PBs has been studied in various parts of the world, and the concentration levels of these compounds clearly depends on the part of the world, industrialization and environmental pollution in the place where the observations were conducted. Furthermore, exposure depends on the degree of consumption of cosmetic products by the studied population, as well as the type of paraben and the matrix tested ${ }^{13,14}$. Previous studies have shown that PBs with a short-chain functional group, such as MePB, $\mathrm{EtPB}$ and/or PrPB, are present in the human body in higher concentrations than other $\mathrm{PBs}^{13}$. The concentration of MePB (the PB observed in the human body in the highest concentration) fluctuates from $0.8 \mathrm{ng} / \mathrm{g}$ in human breast milk in the USA ${ }^{25}$ to $14,187 \mathrm{ng} / \mathrm{g}$ in the hair in Spain ${ }^{13}$, according to the literature. However the knowledge of human exposure to PBs in Poland is extremely scanty and limited to a description of PBs present in human urine $26-28$.

It should be pointed out that an analysis of the hair for the presence of PBs is a relatively new method in toxicology. Previous observations have shown that hair is a suitable matrix to study long term exposure of living organisms to a broad spectrum of toxic substances occurring in the environment ${ }^{13,29,30}$. Moreover, it is known that hair analysis can replace studies on "classic" matrices, such as blood or urine, because it has similar reliability and sensitivity ${ }^{31}$. Simultaneously, the collection of hair samples is easy and completely stress-free, and such samples may be easily stocked and shipped over long distances. It is also known that hair analysis is suitable for the evaluation of exposure to $\mathrm{PBs}^{13,14}$.

Therefore, this study is the first description of an analysis of the hair of Polish residents to simultaneously assess exposure to the most commonly used industrial parabens, such as MePB, EtPB, PrBP, BuPB and BePB using hair samples analysis.

\section{Results}

During the present study, PBs were detected in all hair samples. MePB and PrPB have been noted in all samples studied. In the case of EtPB, the positive percentage was $96.7 \%$. Slightly lower detection rates were noted for BuPB and $\mathrm{BePB}$, where these values amounted to $90 \%$ and $76.7 \%$, respectively. The highest concentration levels were noted in the case of MeBP. The mean concentration level of this substance achieved $4425.3 \pm 10,281.8 \mathrm{pg} / \mathrm{mg}$. The mean concentrations of other PBs studies were significantly lower and did not exceed $1000 \mathrm{pg} / \mathrm{mg}$. These values amounted to $825.7 \pm 2166.0 \mathrm{pg} / \mathrm{mg}, 704.0 \pm 1775.4 \mathrm{pg} / \mathrm{mg}$ and $154.5 \pm 501.1 \mathrm{pg} / \mathrm{mg}$ for PrPB, EtPB and BuPB, respectively. During the present study the lowest concentration level was observed in the case of BePB, which had a mean concentration of $135.2 \pm 144.5 \mathrm{pg} / \mathrm{mg}$. Extreme differences in concentration levels of PBs have been noted between particular volunteers included in the study. These differences were visible in the case all PBs studied, but the largest range of concentration levels concerned MePB (from 87.2 to 42,430.1 pg/mg). Concentration levels of PBs observed during the present study are summarized in Table 1 and illustrated in Fig. 1 (median values).

During the present study some differences in the concentration levels of PBs studied were observed between males and females (Fig. 2). In males, mean concentration levels ( \pm SD) amounted to $4731 \pm 10,289 \mathrm{pg} /$ $\mathrm{mg}$ for $\mathrm{MePB}, 1035 \pm 2309 \mathrm{pg} / \mathrm{mg}$ for $\mathrm{EtPB}, 1115 \pm 2918 \mathrm{pg} / \mathrm{mg}$ for PrPB, $110.4 \pm 71.68 \mathrm{pg} / \mathrm{mg}$ for BePB and $274.1 \pm 746.6 \mathrm{pg} / \mathrm{mg}$ for Bu PB. In women, these values achieved $4137 \pm 10,931 \mathrm{pg} / \mathrm{mg}, 403.3 \pm 1067 \mathrm{pg} / \mathrm{mg}$, $536 \pm 1012 \mathrm{pg} / \mathrm{mg}, 158 \pm 189.5 \mathrm{pg} / \mathrm{mg}$, and $58.73 \pm 79.82 \mathrm{pg} / \mathrm{mg}$, respectively Differences in concentration levels of all PBs studied between men and women were not statistically significant.

During the present study volunteers were also divided into two groups depending on age. The boundary between the groups was set at 35 as this age has traditionally been considered the end of adolescence. At this age, people often change their lifestyle and the aging processes in the body increase. Some differences in concentration levels of PBs were visible between volunteers at the age of 22-35, and persons at the age of 45-67 (Fig. 3). In the first group, the mean concentrations amounted to $3798 \pm 8743 \mathrm{pg} / \mathrm{mg}$ for MePB pg/mg, $186.4 \pm 177.7 \mathrm{pg} /$ $\mathrm{mg}$ for EtPB, $8857 \pm 2748 \mathrm{pg} / \mathrm{mg}$ for PrPB, $112.2 \pm 92.77 \mathrm{pg} / \mathrm{mg}$ for BePB and $63.75 \pm 81.52 \mathrm{pg} / \mathrm{mg}$ for BuPB.

In older volunteers, mean concentration levels of $\mathrm{MePB}, \mathrm{EtPB}, \mathrm{BePB}$ and $\mathrm{BuPB}$ were higher and achieved a level of $5143 \pm 12,395 \mathrm{pg} / \mathrm{mg}, 1341 \pm 2553 \mathrm{pg} / \mathrm{mg}, 160.4 \pm 187.5 \mathrm{pg} / \mathrm{mg}$ and $267.8 \pm 748.2 \mathrm{pg} / \mathrm{mg}$, respectively. In turn, the concentration level of PrBP was lower $(757.1 \pm 1320 \mathrm{pg} / \mathrm{mg})$. However, none of these differences were statistically significant.

During the present study, the comparison of the PB concentration levels in persons with colored hair and persons with natural hair color was also performed (Fig. 4). In persons with colored hair, the mean concentration levels amounted to $5497 \pm 13,888 \mathrm{pg} / \mathrm{mg}$ for $\mathrm{MePB}, 569 \pm 1378 \mathrm{pg} / \mathrm{mg}$ for EtPB, $758.9 \pm 1269 \mathrm{pg} / \mathrm{mg}$ for $\mathrm{PrPB}, 192.2 \pm 228.8 \mathrm{pg} / \mathrm{mg}$ for BePB and $66.61 \pm 96.61 \mathrm{pg} / \mathrm{mg}$ for BuPB. In the group of persons with natural hair color, these values achieved $3966 \pm 8943 \mathrm{pg} / \mathrm{mg}, 764.8 \pm 1958 \mathrm{pg} / \mathrm{mg}, 854.3 \pm 2481 \mathrm{pg} / \mathrm{mg}, 104 \pm 61.56 \mathrm{pg} / \mathrm{mg}$ and $191 \pm 595.2 \mathrm{pg} / \mathrm{mg}$, respectively. These differences were also statistically insignificant.

\section{Discussion}

Obtained results clearly show that people living in north eastern Poland are exposed to various PBs. The present study confirms previous observations that PBs are important environmental pollutants ${ }^{4,32}$. It should be underlined that in Poland, contrary to other countries, information about environmental pollution with parabens, as well as the degree of human exposure to these substances is relatively scanty and limited to only a few studies. It is known that PBs are present in the surface water in Poland ${ }^{33-35}$, and the largest concentration levels were observed in the case of MePB. The concentration levels of this substance in lake water may even achieve $1578 \mathrm{ng} / \mathrm{L}^{33}$. The 


\begin{tabular}{|c|c|c|c|c|c|}
\hline Sample number & Methyl paraben & Ethyl paraben & Propyl paraben & Benzyl paraben & Butyl paraben \\
\hline P1 & 669.2 & 282.3 & 448.6 & 39.4 & 49.3 \\
\hline P2 & 1794.4 & 288.3 & 489.7 & 157.5 & 211.7 \\
\hline P3 & 701.7 & 93.6 & 483.3 & 123.1 & 12.6 \\
\hline $\mathrm{P} 4$ & 791.4 & 447.3 & 58.9 & 36.0 & 99.3 \\
\hline P5 & 87.2 & 19.1 & 24.5 & ND & 4.6 \\
\hline P6 & 556.2 & 59.7 & 32.7 & 40.2 & 10.3 \\
\hline P7 & 663.3 & 52.5 & 22.0 & ND & 8.1 \\
\hline P8 & $42,430.1$ & 4238.2 & 653.6 & 49.3 & 3.8 \\
\hline P9 & 682.8 & 175.7 & 25.7 & ND & 22.1 \\
\hline P10 & 597.9 & 369.0 & 717.6 & 93.0 & 19.8 \\
\hline P11 & 384.2 & 67.1 & 53.9 & 87.2 & 38.2 \\
\hline P12 & $10,661.7$ & 340.2 & 80.0 & 75.1 & 185.5 \\
\hline P13 & 207.7 & 58.2 & 89.8 & ND & 59.0 \\
\hline $\mathrm{P} 14$ & $34,862.4$ & 308.3 & $11,150.3$ & 233.8 & 22.4 \\
\hline $\mathrm{P} 15$ & 371.7 & 38.4 & 160.9 & ND & 12.9 \\
\hline P16 & 610.1 & 608.8 & 21.4 & 67.7 & 4.1 \\
\hline $\mathrm{P} 17$ & $23,704.7$ & 8413.1 & 3582.8 & 121.2 & 2636.0 \\
\hline P18 & 95.4 & ND & 18.9 & 188.5 & ND \\
\hline P19 & 182.8 & 26.1 & 43.2 & ND & ND \\
\hline P20 & 3535.6 & 202.1 & 782.5 & 356.9 & 281.0 \\
\hline P21 & 118.7 & 246.8 & 4077.8 & 700.7 & 45.3 \\
\hline P22 & 645.3 & 26.4 & 264.4 & 52.2 & 17.0 \\
\hline P23 & 492.0 & 104.7 & 165.7 & 117.9 & ND \\
\hline P24 & 204.1 & 120.7 & 207.9 & 74.3 & 132.8 \\
\hline P25 & 151.3 & 25.8 & 48.7 & 193.2 & 23.1 \\
\hline P26 & 679.3 & 36.1 & 173.2 & 63.1 & 32.3 \\
\hline P27 & 551.7 & 47.1 & 205.6 & 103.2 & 13.7 \\
\hline P28 & 182.3 & 47.2 & 62.1 & ND & 27.8 \\
\hline P29 & 5669.7 & 123.3 & 228.5 & 66.9 & 151.4 \\
\hline P30 & 472.9 & 3550.0 & 396.9 & 69.8 & 46.3 \\
\hline \multicolumn{6}{|l|}{ Cumulative data } \\
\hline Median & 604.0 & 120.7 & 169.5 & 87.2 & 27.8 \\
\hline Mean & 4302.0 & 704.0 & 825.7 & 135.2 & 154.5 \\
\hline$\pm \mathrm{SD}$ & $10,281.8$ & 1775.4 & 2166.0 & 144.5 & 501.1 \\
\hline MIN & 87.2 & 19.1 & 18.9 & 36.0 & 3.8 \\
\hline MAX & $42,430.1$ & 8413.1 & $11,150.3$ & 700.7 & 2636.0 \\
\hline LOD (pg/mg) & 0.4 & 1.0 & 0.7 & 1.1 & 0.2 \\
\hline LOQ (pg/mg) & 1.4 & 3.3 & 2.2 & 3.6 & 0.8 \\
\hline$\%$ positive & 100.0 & 96.7 & 100.0 & 76.7 & 90.0 \\
\hline
\end{tabular}

Table 1. Concentration levels of parabens (pg/mg) noted in the hair samples from 30 volunteers (one sample from each volunteer) during the present study. LOD, limit of determination; LOQ, limit of quantification; ND, not detected.

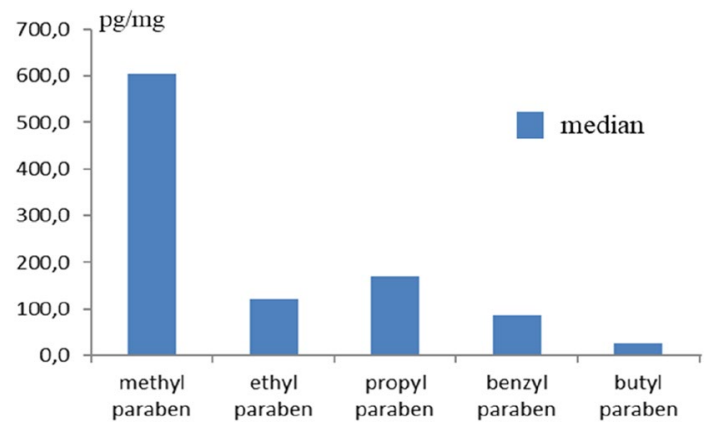

Figure 1. Comparison of median values of parabens included in the present study. 
a) $\mathrm{MePB}$

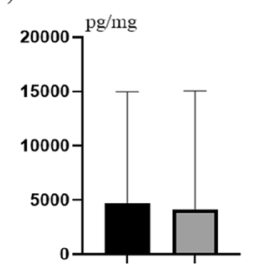

d) $\mathrm{BePB}$
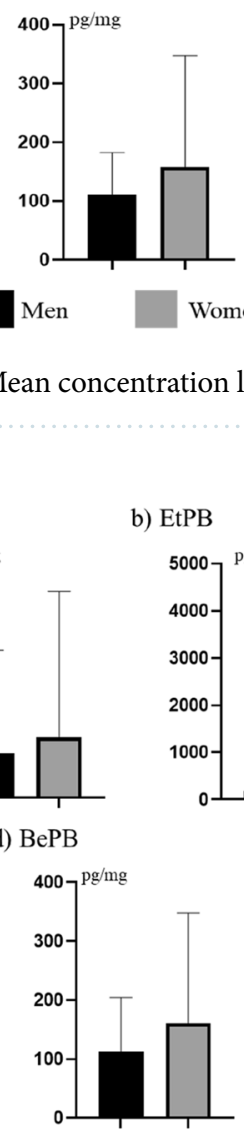

Aged 22-35

Women b) EtPB

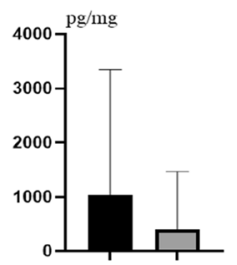

c) $\operatorname{PrPB}$

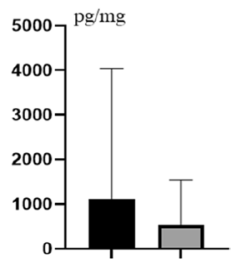

e) BuPB

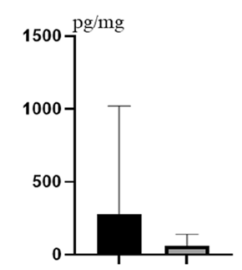

Figure 2. Mean concentration levels $( \pm S D)$ of parabens in hair of men and women.

d) $\mathrm{BePB}$

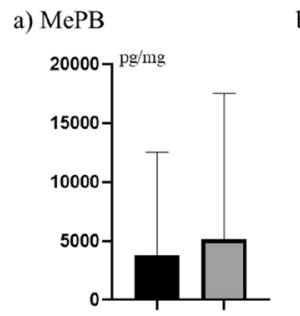

b) EtPB

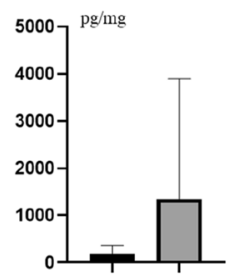

e) BuPB c) $\operatorname{PrPB}$
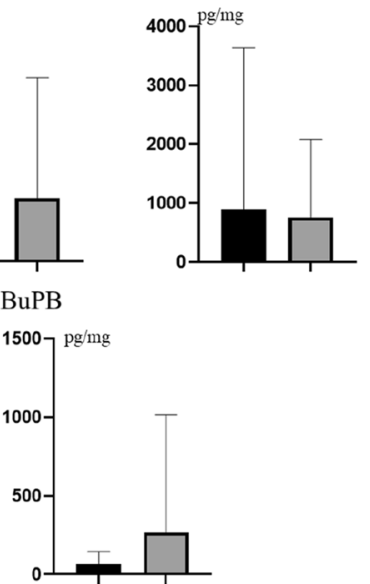

Aged 45-67

Figure 3. Mean concentration levels $( \pm S D)$ of parabens in persons at the age of 22-35 and 45-67.

concentration levels of other PBs in the surface water in Poland are considerably lower, because the maximum concentration levels noted in previous studies amounted to $349 \mathrm{ng} / \mathrm{L}, 165 \mathrm{ng} / \mathrm{L}$ and $23.6 \mathrm{ng} / \mathrm{L}$ for EtPB, PrPB and $\mathrm{BuPB}$, respectively ${ }^{33-35}$. In turn, the relatively high concentration of PBs has been noted in wastewater in southern Poland, in which concentration levels of MePB, EtPB, PrBP and BuPB fluctuated within limits of 2235.0-40,898.6 ng/L, 791.2-8169.4 ng/L, 542.2-7803.3 ng/L and 68.8-710.7 ng/L, respectively ${ }^{35}$. It should be noted that pollution of the natural environment with PBs is correlated with the risk of human exposure to these substances. Therefore, the above-mentioned data confirm that the inhabitants of Poland are exposed to the adverse effects of parabens, not only contained, for example, in cosmetics, but also polluting the environment. Knowledge concerning biomonitoring of human exposure to PBs in people living in Poland are also extremely scanty and limited to only three studies ${ }^{26-28}$. These studies have described concentration levels of selected PBs in human urine. In women the mean concentration levels were $107.9 \mu \mathrm{g} / \mathrm{L}$ for MePB, $12.9 \mu \mathrm{g} / \mathrm{L}$ for EtPB, $18.67 \mu \mathrm{g} / \mathrm{L}$ for $\mathrm{PrPB}, 5.02 \mu \mathrm{g} / \mathrm{L}$ for BuPB and $2.8 \mu \mathrm{g} / \mathrm{L}$ for izobutylparaben (iPB) ${ }^{28}$. In men, concentration levels of the majority of PBs were slightly lower and depended on the study. According to one study, the average concentration of PBs in male urine amounted to $47.6 \mu \mathrm{g} / \mathrm{L}$ for MeBP, $8.6 \mu \mathrm{g} / \mathrm{L}$ for EtPB, $22.3 \mu \mathrm{g} / \mathrm{L}$ for PrBP, $1.4 \mu \mathrm{g} / \mathrm{L}$ for BuPB and $1.1 \mu \mathrm{g} / \mathrm{L}$ for $\mathrm{iPB}^{26}$, and according to a subsequent investigation, these values achieved $15.6 \mu \mathrm{g} / \mathrm{L}, 9.39 \mu \mathrm{g} / \mathrm{L}$, $3.7 \mu \mathrm{g} / \mathrm{L}, 3.48 \mu \mathrm{g} / \mathrm{L}$ and $2.27 \mu \mathrm{g} / \mathrm{L}$, respectively ${ }^{27}$.

However, it is relatively well established that the degree of human exposure to PBs clearly depends on the area where the studies have been performed ${ }^{13,14,36,37}$. For example, the levels of MeBP noted in human urine in Australia fluctuated from 74.4 to $1180 \mathrm{ng} / \mathrm{g}^{36}$, while in Brazil it was in the range of $0.82-26.15 \mathrm{ng} / \mathrm{g}^{37}$. Extreme 


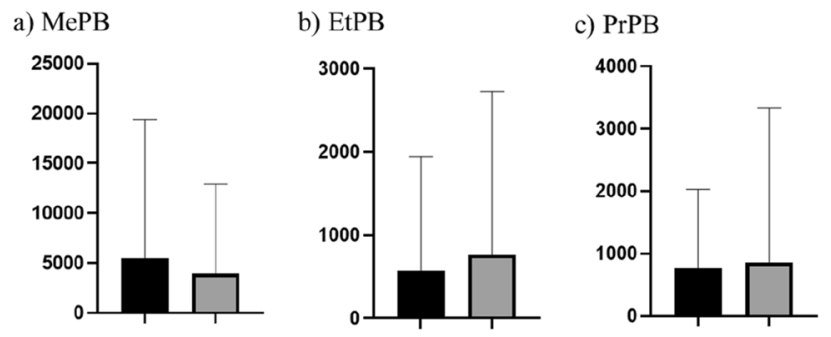

d) $\mathrm{BePB}$

e) $\mathrm{BuPB}$
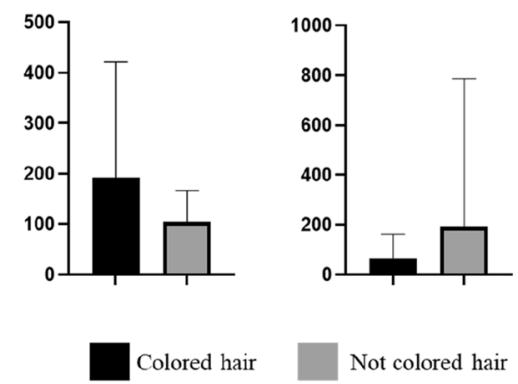

Figure 4. Mean concentration levels $( \pm S D)$ of parabens in persons with colored hair and natural hair color.

\begin{tabular}{|c|c|c|c|c|c|c|c|}
\hline Country & $\mathbf{n}$ & MePB & EtPB & PrPB & BePB & BuPB & References \\
\hline Germany & 4 & & $810-1980$ (1365) & $400-1520(940)$ & & & 40 \\
\hline Greece & 95 & \begin{tabular}{|l}
$17.6-27,437.0$ \\
$(4501.2)$
\end{tabular} & $\begin{array}{l}11.0-4224.5 \\
(510.1)\end{array}$ & & $2.1-66.6(22.9)$ & $1.8-2513.7(237.1)$ & 13 \\
\hline Korea & 10 & $48.3-224.2(123.6)$ & $11.5-158.3(64.5)$ & $70.2-214.5(136.9)$ & $15.3-100.2(55.6)$ & 25.4-111.1 (74.2) & 41 \\
\hline \multirow{3}{*}{ Spain } & 6 & $78-624(246.5)$ & 7.0-42 (19.83) & $27-238(140.83)$ & & & 42 \\
\hline & 6 & $10.2-33(20.7)$ & $9(9)$ & $11.6-107(66.9)$ & & $3.5-9.4(5.76)$ & 38 \\
\hline & 42 & $\begin{array}{l}68.3-14,187 \\
(2820.7)\end{array}$ & $2.9-6565(634.8)$ & $12.5-9009(1006.1)$ & & & 14 \\
\hline Poland & 30 & \begin{tabular}{|l|}
$87.2-42,430.1$ \\
$(4302.0)$
\end{tabular} & $\begin{array}{l}19.1-8413.1 \\
(704.0)\end{array}$ & $\begin{array}{l}18.9-11,150.3 \\
(825.7)\end{array}$ & $36.0-700.7(135.2)$ & $3.8-2636.0(154.5)$ & Current study \\
\hline
\end{tabular}

Table 2. Ranges and means (in brackets) of the concentration of parabens in human hair samples (pg/mg) noted in previous observations and the present study. $n$ number of samples included into the study.

differences in the concentration of PBs have also been noted between people living in the same country. For instance, the levels of MePB in human hair from Spain varied from 10.2 to $33 \mathrm{ng} / \mathrm{g}^{38}$, and according to another observation it ranged from 68.3 to $14,187 \mathrm{ng} / \mathrm{g}^{14}$. These facts, together with clear differences in particular persons included into previous studies ${ }^{14,39}$ and the present investigation strongly suggest that the degree of exposure to PBs depends on various factors in the immediate human environment. These factors are not fully specified, but may include among others the frequency of cosmetics use, food, medications, profession and/or home furnishing. The concentrations noted during the present study were relatively high, although Olsztyn, where this study was performed, is not a highly industrialized region. So, high levels of the PBs noted in this study are not related to the degree of industrialization and the resulting pollution of the environment.

Up to now, only a few studies concerning biomonitoring of human exposure to PBs through hair sample analysis have been published (Table 2).

The values noted in the present study in comparison to previous observations (Table 2) are higher. It is best proven by the fact that the maximum concentration for all PBs studied noted in the present observation have not yet been described at this level. This phenomenon is most visible in the case of BePB (Table 2). However, the present study confirms previous observations (Table 2) that hair analysis is a suitable method to evaluate human exposure to PBs and may be used instead of the analysis of "classic" matrices, such as urine or blood. Undoubtedly, ease of collection and storage of samples speak for the use of hair analysis.

Moreover, the present results confirm two aspects connected with human exposure to PBs. The first of them is the fact that PBs with short-chain functional groups (such as MePB, EtPB and PrPB) are present in the human organism in the highest concentrations, and therefore their adverse effects may have the most important influence on human health status. This is because such parabens are the most commonly used in the industry, which leads to relatively high environmental pollution with these substances ${ }^{1,20}$. The second observation is that the human body is exposed simultaneously to some PBs. This fact, noted both in the present study, where exposure to at least three $\mathrm{PBs}$ was noted in all samples and in previous observations ${ }^{13,14,38}$, is very important in terms of toxicology. It 
is relatively well known that exposure to several chemicals may have adverse effects different from exposure to a single substance. This is because of interactions between chemicals, which may lead to a possible synergistic or additive effect ${ }^{4,20,43}$. It should be remembered that such a situation may occur not only between particular PBs, but also between PBs and other endocrine disruptors commonly found in the environment, such as bisphenol A, triclosan or polyfluoroalkyl substances ${ }^{14,44-46}$. Therefore, even moderate levels of single PBs, but with the simultaneous presence of other PBs and other types of endocrine disruptors, may affect human health. This is all the more likely since multidirectional adverse effects of PBs have been reported by an increasing number of studies $^{11,17-21}$, and many aspects connected with the toxic activity of these substances are still not fully understood.

Differences in the concentration of PBs between men and women and between younger and older persons noted in the present study were not statistically significant. In the light of previous studies, it is known that higher levels of BPs are present in women ${ }^{14,26-28,47}$. This phenomenon is explained by the fact that women use a high number of cosmetics containing parabens not used by men (make-up, creams and mouthwash). On the other hand, previous observations have shown that men are also to a large extent exposed to PBs by the use of $\operatorname{cosmetics}^{48-50}$, and no statistically significant differences in PB levels between men and women were observed in the present study, which confirms the previous observations. Moreover, previous studies have found that concentrations of PBs in older humans are higher than in younger people ${ }^{14}$, due to the fact that older people most often use personal care products. The present results support this thesis, but only partially. Although the mean level of most PBs studied were higher in older persons in comparison to young adults, the differences between these two groups were not statistically significant.

Moreover, during the present study no statistically significant differences in the concentrations of PBs were noted between persons with colored hair and persons with uncolored hair. It proves that the proper preparation of hair samples (mainly thorough washing in ultrapure water and methanol) removes any external contamination from the hair, and therefore hair sample analysis is a suitable method of biomonitoring human exposure to $\mathrm{PBs}$, which is in agreement with previous observations ${ }^{13,14}$.

However, this study has some limitations. The first is the number of volunteers included into the experiment. Although many previous studies on exposure to organic pollutants have been conducted on similar or even smaller populations ${ }^{31,41,51,52}$, it is commonly known that the larger the study group, the more representative the results will be. For this reason, the present study may be considered preliminary, and the exact monitoring of human exposure to $\mathrm{PBs}$ in various regions of Poland requires further research. The next limitation is connected with the fact that fur analysis takes into account both external and internal exposure, and the separation of externally deposited compounds from endogenously deposited substances is difficult. External exposure may depend on how long the hair was on the head (distance from the scalp). Although the hair samples in this study were collected from the same place on the head near the scalp, the hairs had various length (depending on the hairstyle). This fact may have had an influence on the levels of PBs, because longer hair is exposed to environmental factors for longer, which may lead to higher concentrations of substances studied. On the other hand, during the present study there were no strict correlations between hair length and PB levels (Tables 1, 3). For example, in sample number P17 (hair length $0.5 \mathrm{~cm}$ ) the concentration was extremely higher than in sample P10 (hair length 12-14 cm). Nevertheless, this study showed human exposure to PBs, and the exact description of the correlation between hair length and concentration of PBs needs further studies.

To sum up, the obtained results have shown that inhabitants of Olsztyn and the surrounding area (northern east Poland) are simultaneously exposed to various PBs. Simultaneous exposure to some PBs is important in terms of toxicology, because substances may interact with each other. Such a situation may lead to a possible synergistic or additive adverse effect on the human organism. The presence of PBs strongly suggests that these substances have an influence on human health. Moreover, the present study confirms previous observations that analysis of the hair samples is a suitable method for the biomonitoring of human exposure to PBs. However, the above mentioned limitations of this study suggests that the exact explanations of all the aspects connected with the presence of PBs in human hair in Poland requires further study.

\section{Materials and methods}

Materials. MePB, EtPB , PrBP , BuPB, BePB (all $\geq 99 \%$ ), and ammonium acetate $(\geq 98 \%)$ were purchased from Sigma-Aldrich (St. Louis, MO, USA), methanol (LC-MS grade) from Honeywell-Riedel de Haën (Seelze, Germany), acetonitrile (LC-MS grade) from Fisher Chemical and phenobarbital- $\mathrm{d}^{5}$ from Isotec Inc. (Miamisburg, OH, USA). Ultrapure water was produced by Merck's Direct-Q 3UVwater purification system (Darmstadt, Germany).

Sample collection. Head hair samples were collected from 30 volunteers-adult persons of both genders ( 15 women and 15 men), aged between 22 and 67, residents of Olsztyn (city in north-eastern Poland) and the surrounding area. Information about volunteers are shown in Table 3. Before collection of samples all people were informed about the study and agreed to the sampling procedure. Sampling collection was performed according to the agreements of the Bioethical Committee at the School of Medicine of the University of Warmia and Mazury in Olsztyn (Poland) (agreement numbers: 27/2017 and 5/2021). The studies were performed with informed consent. All experimental methods were applied in accordance with the relevant guidelines and European and Polish regulations. Hair samples were collected from the back of the head above the nape of the neck, near the scalp, and differences in the hair length were due to the different hairstyles of the volunteers. Immediately after collection, hair samples (about $2 \mathrm{~g}$ ) were wrapped in aluminum foil and stored in the dark at room temperature until further studies. During storage, samples did not come into contact with materials containing parabens. 


\begin{tabular}{|c|c|c|c|c|c|}
\hline No & Age & Gender & Colour & Hair coloring & Length $(\mathrm{cm})$ \\
\hline 1 & 46 & Male & Black & No & $1-2$ \\
\hline 2 & 45 & Male & Black & No & $3-4$ \\
\hline 3 & 28 & Female & Brown & Yes & 3 \\
\hline 4 & 23 & Male & Black & No & $8-9$ \\
\hline 5 & 32 & Male & Black & No & $2-3$ \\
\hline 6 & 34 & Male & Black & No & 1 \\
\hline 7 & 50 & Female & Blond & Yes & $3-4$ \\
\hline 8 & 53 & Female & Black & Yes & $3-4$ \\
\hline 9 & 28 & Male & Black & No & $3-4$ \\
\hline 10 & 22 & Female & Blond & No & $12-14$ \\
\hline 11 & 27 & Female & Black & No & $7-9$ \\
\hline 12 & 24 & Female & Brown & No & 7 \\
\hline 13 & 23 & Female & Brown & No & 7 \\
\hline 14 & 23 & Male & Brown & No & 0.5 \\
\hline 15 & 61 & Male & Black-Gray & No & 1 \\
\hline 16 & 35 & Male & Black & No & 1 \\
\hline 17 & 55 & Male & Black-Gray & No & 0.5 \\
\hline 18 & 49 & Male & Black & No & $6-7$ \\
\hline 19 & 23 & Male & Brown & No & 11 \\
\hline 20 & 22 & Female & Black-Brown & Yes & 5 \\
\hline 21 & 56 & Female & Brown & Yes & $3-4$ \\
\hline 22 & 55 & Female & Brown-Red & Yes & $5-6$ \\
\hline 23 & 48 & Female & Brown & Yes & $3-4$ \\
\hline 24 & 46 & Female & Black & Yes & $8-10$ \\
\hline 25 & 50 & Male & Grey & No & 0.5 \\
\hline 26 & 31 & Female & Brown & Yes & - \\
\hline 27 & 27 & Female & Brown & No & $6-7$ \\
\hline 28 & 67 & Female & White & No & 6 \\
\hline 29 & 34 & Male & Black & No & 0.5 \\
\hline 30 & 59 & Male & Black & No & 3 \\
\hline
\end{tabular}

Table 3. Characterization of volunteers taking part in the study.

Extraction of PBs from hair. Hair samples were washed four times (twice with ultrapure water and twice in methanol) to remove external contamination from the hair. Then the hair samples were dried and cut into small pieces. The extraction was performed according to the method previously described by Tzatzarakis et al. ${ }^{53}$. In short, $100 \mathrm{mg}$ of each sample were put into glass screw tubes, treated with $2 \mathrm{ml}$ of methanol and subjected to extraction in an ultrasonic water bath for $4 \mathrm{~h}$ with periodic mixing with a vortex system. After centrifugation, the extract was put in glass tubes and evaporated to dryness under nitrogen steam at $35^{\circ} \mathrm{C}$. Then $100 \mu$ of methanol was added to residues and the solution was transferred into $2 \mathrm{ml}$ vials for liquid chromatography-mass spectrometry (LC-MS) analysis.

Instrumentation. Analysis was performed with a Shimadzu (Kyoto, Japan) liquid chromatography-mass spectrometry system (LC-MS $2010 \mathrm{EV}$ ) equipped with an autosampler. Analyte separation was performed using a Supelco Discovery column C18 $(250 \mathrm{~mm}, 4.6 \mathrm{~mm}, 5 \mu \mathrm{m})$ (Sigma-Aldrich, St. Louis, MO, USA) at $30^{\circ} \mathrm{C}$ stable oven temperature. A gradient of $5 \mathrm{mM}$ ammonium acetate (solvent $\mathrm{A}$ ) and acetonitrile (solvent $\mathrm{B}$ ) were chosen for the analysis with a flow rate $0.6 \mathrm{ml} / \mathrm{min}$. Atmospheric pressure chemical ionization (APCI) combined with a quadrapole mass filter in a selected ion monitoring (SIM) negative mode were used for monitoring the aforementioned substances.

Method validation. To ensure the efficacy of the method used in the present study, analytical parameters were checked. Standard solutions of the analytes were performed in concentrations of $0,50,100,250$ and $500 \mathrm{ng} /$ ml. Linearity of the standard solutions was found to be 0.999 for MePB, 0.9985 for EtPB, 0.9969 for PrPB, 0.9997 for $\mathrm{BePB}$ and 0.9988 for BuPB. Spiked samples were also performed in concentrations of $0,50,100,250$ and $500 \mathrm{pg} / \mathrm{mg}$. Linearity was found at 0.9987 form MePB, 0.9867 for EtPB, 0.9979 for PrBP, 0.9920 for BePB and 0.9945 for BuPB.

Limit of detection (LOD) and limit of quantification (LOQ) were calculated using the signal to noise ratio. Recovery, accuracy and inter day precision (\%RSD) of the method were examined using 3 repeats of spiked samples $(\mathrm{n}=3)$ for each above-mentioned tested concentration $(50,100,250$ and $500 \mathrm{pg} / \mathrm{mg})$ (Table 4). 


\begin{tabular}{|l|c|l|l|l|l|}
\hline $\mathbf{n}=\mathbf{3}$ & Methyl paraben & Ethyl paraben & Propyl paraben & Benzyl paraben & Butyl paraben \\
\hline Mean \% recovery & 125.0 & 90.7 & 99.7 & 83.4 & 107.0 \\
\hline$\pm \mathrm{SD}$ & 4.4 & 16.3 & 8.2 & 15.9 & 12.4 \\
\hline Mean \% accuracy & 102.2 & 105.8 & 109.7 & 84.5 & 109.6 \\
\hline$\pm \mathrm{SD}$ & 3.3 & 20.4 & 11.3 & 14.9 & 14.6 \\
\hline Precision (\% RSD) & 15.8 & 12.7 & 14.0 & 21.9 & 9.5 \\
\hline$\pm \mathrm{SD}$ & 4.7 & 6.9 & 10.6 & 2.9 & 4.2 \\
\hline LOD (pg/mg) & 0.4 & 1.0 & 0.7 & 1.1 & 0.2 \\
\hline LOQ (pg/mg) & 1.4 & 3.3 & 2.2 & 3.6 & 0.8 \\
\hline $\mathrm{r}^{2}$ (spiked curves) & 0.9987 & 0.9867 & 0.9979 & 0.9920 & 0.9945 \\
\hline $\mathrm{r}^{2}$ (standard curves) & 0.9990 & 0.9985 & 0.9969 & 0.9997 & 0.9988 \\
\hline
\end{tabular}

Table 4. Validation parameters of the applied methodology.

Statistical analysis. The statistical analysis was performed using GraphPad Prism version 9.2.0 (GraphPad Software, San Diego, California USA). In the case of a comparison between two groups (males versus females, younger volunteers versus their elders, persons with colored hair versus persons with natural hair color) non parametric Mann-Whitney test was used. The differences were considered statistically significant at $p<0.05$.

Received: 26 August 2021; Accepted: 24 November 2021

Published online: 08 December 2021

\section{References}

1. Kirchhof, M. G. \& de Gannes, G. C. The health controversies of parabens. Skin Ther. Lett. 18, 5-7 (2013).

2. Peng, X. et al. Discovery of a marine bacterium producing 4-hydroxybenzoate and its alkyl esters, parabens. Appl. Environ. Microbiol. 72, 5556-5561 (2006).

3. Yazar, K., Johnsson, S., Lind, M. L., Boman, A. \& Lidén, C. Preservatives and fragrances in selected consumer-available cosmetics and detergents. Contact Dermat. 64, 265-272 (2011).

4. Fransway, A. F. et al. Parabens. Dermatitis 30, 3-31 (2019).

5. Arachchige Chamila Samarasinghe, S. V., Krishnan, K., Aitken, R. J., Naidu, R. \& Megharaj, M. Persistence of the parabens in soil and their potential toxicity to earthworms. Environ. Toxicol. Pharmacol. 83, 103574 (2021).

6. Feng, J., Zhao, J., Xi, N., Guo, W. \& Sun, J. Parabens and their metabolite in surface water and sediment from the Yellow River and the Huai River in Henan Province: spatial distribution, seasonal variation and risk assessment. Ecotoxicol. Environ. Saf. 172, 480-487 (2019).

7. Malvar, J. L., Santos, J. L., Martín, J., Aparicio, I. \& Alonso, E. Routine analytical method for monitoring the main metabolites for a recurrent group of parabens and pharmaceuticals in wastewater and tap water. Anal. Bioanal. Chem. 411, 6625-6635 (2019).

8. Chiesa, L. M., Pavlovic, R., Panseri, S. \& Arioli, F. Evaluation of parabens and their metabolites in fish and fish products: a comprehensive analytical approach using LC-HRMS. Food Addit. Contam. Part A Chem. Anal. Control. Expo. Risk Assess. 35, 2400-2413 (2018).

9. Karthikraj, R., Borkar, S., Lee, S. \& Kannan, K. Parabens and their metabolites in pet food and urine from New York State, United States. Environ. Sci. Technol. 52, 3727-3737 (2018).

10. Nobile, M. et al. Presence of emerging contaminants in baby food. Food Addit. Contam. Part A Chem. Anal. Control. Expo. Risk. Assess 37, 131-142 (2020).

11. Kolatorova, L. et al. Exposure to bisphenols and parabens during pregnancy and relations to steroid changes. Environ. Res. 163, 115-122 (2018).

12. Song, S. et al. Profiles of parabens and their metabolites in paired maternal-fetal serum, urine and amniotic fluid and their implications for placental transfer. Ecotoxicol. Environ. Saf. 191, 110235 (2020).

13. Karzi, V. et al. Investigating exposure to endocrine disruptors via hair analysis of pregnant women. Environ. Res. 178, 108692 (2019).

14. Martín, J., Santos, J. L., Aparicio, I. \& Alonso, E. Exposure assessment to parabens, bisphenol A and perfluoroalkyl compounds in children, women and men by hair analysis. Sci. Total Environ. 695, 133864 (2019).

15. Güzel Bayülken, D. \& Ayaz Tüylü, B. In vitro genotoxic and cytotoxic effects of some paraben esters on human peripheral lymphocytes. Drug Chem. Toxicol. 42, 386-393 (2019).

16. Roszak, J. et al. Cytotoxic effects in transformed and non-transformed human breast cell lines after exposure to silver nanoparticles in combination with selected aluminium compounds, parabens or phthalates. J. Hazard. Mater. 392, 122442 (2020).

17. Bairati, C., Goi, G., Lombardo, A. \& Tettamanti, G. The esters of p-hydroxy-benzoate (parabens) inhibit the release of lysosomal enzymes by mitogen-stimulated peripheral human lymphocytes in culture. Clin. Chim. Acta. 224, 147-157 (1994).

18. Shaw, J. \& de Catanzaro, D. Estrogenicity of parabens revisited: impact of parabens on early pregnancy and an uterotrophic assay in mice. Reprod. Toxicol. 28, 26-31 (2009).

19. Nowak, K., Jabłońska, E. \& Ratajczak-Wrona, W. Immunomodulatory effects of synthetic endocrine disrupting chemicals on the development and functions of human immune cells. Environ. Int. 125, 350-364 (2019).

20. Petric, Z., Ružić, J. \& Žuntar, I. The controversies of parabens-An overview nowadays. Acta Pharm. 71, 17-32 (2021).

21. Jiang, Y. et al. Prenatal exposure to benzophenones, parabens and triclosan and neurocognitive development at 2 years. Environ. Int. 126, 413-421 (2019).

22. Charles, A. K. \& Darbre, P. D. Combinations of parabens at concentrations measured in human breast tissue can increase proliferation of MCF-7 human breast cancer cells. J. Appl. Toxicol. 33, 390-398 (2013).

23. Roje, $\check{Z}$ et al. Synergistic effects of parabens and plastic nanoparticles on proliferation of human breast cancer cells. Arh. Hig. Rada. Toksikol. 70, 310-314 (2019).

24. Scientific Committee on Consumer Safety (SCCS), Opinion on Parabens https://ec.europa.eu/health/scientific_committees/consu mer_safety/docs/sccs_o_041.pdf (2010). 
25. Hines, H. P. et al. Concentrations of environmental phenols and parabens in milk, urine and serum of lactating North Carolina women. Reprod. Toxicol. 54, 120-128 (2015).

26. Jurewicz, J. et al. Environmental exposure to parabens and sperm chromosome disomy. Int. J. Environ. Health Res. 27, 332-343 (2017).

27. Jurewicz, J. et al. Human semen quality, sperm DNA damage, and the level of reproductive hormones in relation to urinary concentrations of parabens. J. Occup. Environ. Med. 59, 1034-1040 (2017).

28. Jurewicz, J. et al. Parameters of ovarian reserve in relation to urinary concentrations of parabens. Environ. Health 19, 26 (2020).

29. Tzatzarakis, M. N. et al. Hair nicotine/cotinine concentrations as a method of monitoring exposure to tobacco smoke among infants and adults. Hum. Exp. Toxicol. 31, 258-265 (2012).

30. Renieri, E. A. et al. Indicator PCBs in farmed and wild fish in Greece-risk assessment for the Greek population. Food Chem. Toxicol. 127, 260-269 (2019).

31. Alves, A., Jacobs, G., Vanermen, G., Covaci, A. \& Voorspoels, S. New approach for assessing human perfluoroalkyl exposure via hair. Talanta 144, 574-583 (2015).

32. Błędzka, D., Gromadzińska, J. \& Wąsowicz, W. Parabens. From environmental studies to human health. Environ. Int. 67, 27-42 (2014).

33. Czarczyńska-Goślińska, B., Zgoła-Grześkowiak, A., Jeszka-Skowron, M., Frankowski, R. \& Grześkowiak, T. Detection of bisphenol A, cumylphenol and parabens in surface waters of Greater Poland Voivodeship. J. Environ. Manag. 204, 50-60 (2017).

34. Zgoła-Grześkowiak, A., Jeszka-Skowron, M., Czarczyńska-Goślińska, B. \& Grześkowiak, T. Determination of Parabens in Polish River and Lake Water as a Function of Season. Anal. Lett. 11, 1734-1747 (2016).

35. Styszko, K., Proctor, K., Castrignanò, E. \& Kasprzyk-Hordern, B. Occurrence of pharmaceutical residues, personal care products, lifestyle chemicals, illicit drugs and metabolites in wastewater and receiving surface waters of Krakow agglomeration in South Poland. Sci. Total Environ. 768, 144360 (2021).

36. Heffernan, A. L. et al. Use of pooled samples to assess human exposure to parabens, benzophenone-3 and triclosan in Queensland, Australia. Environ. Int. 85, 77-83 (2015).

37. Jardim, V.C., de Paula Melo, L., Soares Domingues, D. \& Costa Queiroz, M. E. Determination of parabens in urine samples by microextraction using packed sorbent and ultra-performance liquid chromatography coupled to tandem mass spectrometry. J. Chromatogr. B Anal. Technol. Biomed. Life Sci. 974, 35-41 (2015).

38. Rodríguez-Gómez, R. et al. Biomonitoring of 21 endocrine disrupting chemicals in human hair samples using ultra-high performance liquid chromatography tandem mass spectrometry. Chemosphere 168, 676-684 (2017).

39. Asimakopoulos, A. G., Thomaidis, N. S. \& Kannan, K. Widespread occurrence of bisphenol A diglycidyl ethers, p-hydroxybenzoic acid esters (parabens), benzophenone type-UV filters, triclosan, and triclocarban in human urine from Athens, Greece. Sci. Total Environ. 470-471, 1243-1249 (2014).

40. Martín, J., Moeder, M., Gaudl, A., Alonso, E. \& Reemtsma, T. Multi-class method for biomonitoring of hair samples using gas chromatography-mass spectrometry. Anal. Bioanal. Chem. 407, 8725-8734 (2015).

41. Cho, S. H. \& Song, H. N. Development of a liquid chromatography/tandem mass spectrometry method for monitoring of longterm exposure to parabens. Rapid Commun. Mass Spectrom. 33, 67-73 (2019).

42. Martín, J., Santos, J. L., Aparicio, I. \& Alonso, E. Analytical method for biomonitoring of endocrine-disrupting compounds (bisphenol A, parabens, perfluoroalkyl compounds and a brominated flame retardant) in human hair by liquid chromatography-tandem mass spectrometry. Anal. Chim. Acta 945, 95-101 (2016)

43. van Meeuwen, J. A., van Son, O., Piersma, A. H., de Jong, P. C. \& van den Berg, M. Aromatase inhibiting and combined estrogenic effects of parabens and estrogenic effects of other additives in cosmetics. Toxicol. Appl. Pharmacol. 230, 372-382 (2008).

44. Katsikantami, I. et al.. Biomonitoring of bisphenols A and S and phthalate metabolites in hair from pregnant women in Crete. Sci. Total. Environ. 712, 135651 (2020).

45. Karzi, V. et al. Biomonitoring of bisphenol A, triclosan and perfluorooctanoic acid in hair samples of children and adults. J. Appl. Toxicol. 38, 1144-1152 (2018).

46. Makowska, K. et al. Assessment of exposure to perfluoroalkyl substances (PFASs) in dogs by fur analysis. Environ. Pollut. 286, 117435 (2021)

47. Engel, L. S. et al. Predictors and variability of repeat measurements of urinary phenols and parabens in a cohort of Shanghai women and men. Environ. Health Perspect. 122, 733-740 (2014).

48. Frederiksen, H., Jørgensen, N. \& Andersson, A. M. Parabens in urine, serum and seminal plasma from healthy Danish men determined by liquid chromatography-tandem mass spectrometry (LC-MS/MS). J. Expo. Sci. Environ. Epidemiol. 21, 262-271 (2011).

49. Nassan, F. L. et al. Personal care product use in men and urinary concentrations of select phthalate metabolites and parabens: results from the environment and reproductive health (EARTH) study. Environ. Health Perspect. 125, 087012 (2017).

50. Hajizadeh, Y., Kiani Feizabadi, G. \& Feizi, A. Exposure to parabens through the use of personal care products among Iranian men. Arch. Environ. Contam. Toxicol. 80, 587-600 (2021).

51. Perez, F., Llorca, M., Farré, M. \& Barceló, D. Automated analysis of perfluorinated compounds in human hair and urine samples by turbulent flow chromatography coupled to tandem mass spectrometry. Anal. Bioanal. Chem. 402, 2369-2378 (2012).

52. Lee, C., Kim, C. H., Kim, S. \& Cho, S. H. Simultaneous determination of bisphenol A and estrogens in hair samples by liquid chromatography-electrospray tandem mass spectrometry. J. Chromatogr. B Analyt. Technol. Biomed. Life Sci. 1058, 8-13 (2017).

53. Tzatzarakis, M. N. et al. Biomonitoring of bisphenol A in hair of Greek population. Chemosphere 118, 336-341 (2015).

\section{Acknowledgements}

Authors are grateful to the volunteers who participated in this study.

\section{Author contributions}

J.W. supervision of the study, sample collection, obtaining the content from bioethical committee, writing of the manuscript; M.T. and V.E. methodology, analysis performance, editing of the manuscript; K.M. statistical analysis, editing of the manuscript, S.G. conceptualization participation in writing of the manuscript, literature research.

\section{Funding}

The Statutory Fund of the School of Medicine, Collegium Medicum (61.610.001-300), University of Warmia and Mazury in Olsztyn.

\section{Competing interests}

The authors declare no competing interests. 


\section{Additional information}

Correspondence and requests for materials should be addressed to J.W.

Reprints and permissions information is available at www.nature.com/reprints.

Publisher's note Springer Nature remains neutral with regard to jurisdictional claims in published maps and institutional affiliations.

(c) (1) Open Access This article is licensed under a Creative Commons Attribution 4.0 International License, which permits use, sharing, adaptation, distribution and reproduction in any medium or format, as long as you give appropriate credit to the original author(s) and the source, provide a link to the Creative Commons licence, and indicate if changes were made. The images or other third party material in this article are included in the article's Creative Commons licence, unless indicated otherwise in a credit line to the material. If material is not included in the article's Creative Commons licence and your intended use is not permitted by statutory regulation or exceeds the permitted use, you will need to obtain permission directly from the copyright holder. To view a copy of this licence, visit http://creativecommons.org/licenses/by/4.0/.

(C) The Author(s) 2021 